This item was submitted to Loughborough's Research Repository by the author.

Items in Figshare are protected by copyright, with all rights reserved, unless otherwise indicated.

\title{
Effect of pressure wave disturbance on auto-ignition mode transition and knocking intensity under enclosed conditions
}

PLEASE CITE THE PUBLISHED VERSION

http://dx.doi.org/10.1016/j.combustflame.2017.07.004

\section{PUBLISHER}

Elsevier () The Combustion Institute

VERSION

AM (Accepted Manuscript)

\section{PUBLISHER STATEMENT}

This work is made available according to the conditions of the Creative Commons Attribution-NonCommercialNoDerivatives 4.0 International (CC BY-NC-ND 4.0) licence. Full details of this licence are available at: https://creativecommons.org/licenses/by-nc-nd/4.0/

\section{LICENCE}

CC BY-NC-ND 4.0

\section{REPOSITORY RECORD}

Pan, Jiaying, Haiqiao Wei, Gequn Shu, and Rui Chen. 2017. "Effect of Pressure Wave Disturbance on Autoignition Mode Transition and Knocking Intensity Under Enclosed Conditions”. figshare. https://hdl.handle.net/2134/26093. 


\title{
Effect of pressure wave disturbance on auto-ignition mode transition and knocking intensity under enclosed conditions
}

\author{
Jiaying Pan, Haiqiao Wei*, Gequn Shu, Rui Chen \\ State Key Laboratory of Engines, Tianjin University, Tianjin 300072, China
}

Accepted for publication By Combustion and Flame

\begin{abstract}
Pressure wave propagation behavior is an essential feature for the combustion under enclosed conditions, e.g. internal combustion engines. Previous work by Pan et al. (2016) and Yu et al. (2015) showed that pressure wave disturbance not only affects hot-spot formation and knocking origin, but also induces detonation wave through a coupling mechanism between pressure wave and flame front. On this basis, this study further investigates the role of pressure wave disturbance in autoignition mode and knocking intensity by means of detailed numerical simulations with stoichiometric $\mathrm{H}_{2}$ /air mixture. Firstly, the pressure waves with different levels in strength have been obtained by adjusting ignition temperature of hot ignition kernel. It shows that as ignition temperature is raised at each initial temperature, pressure wave strength is decreased monotonously, with declining compression ratio and temperature rise caused by pressure wave disturbance. Secondly, three autoignition modes have been observed with the variations of pressure wave strength, i.e. detonation, mixed mode and supersonic deflagration. As the weakness of pressure wave strength, there is an auto-ignition mode transition from detonation to supersonic deflagration, accompanied by rapid decreases in pressure peak, obvious pre-flame partial reaction and significant increases in autoignition reaction front speed. These observations are still maintained at elevated initial pressure conditions. Finally, such auto-ignition modes and knocking intensity for the detailed computations are summarized in the non-dimensional Bradley's diagram. The results show that both auto-ignition mode and initial thermodynamic state can affect knocking intensity, and the modifications in knocking intensity by pressure wave disturbance are mainly through auto-ignition mode transition. This is qualitatively consistent with the distribution of combustion regimes in Bradley's diagram, even though some deviations do exist because the diagram is constructed on basis of initially nonreactive flows.
\end{abstract}

"correspondence author:whq@tju.edu.cn 


\section{Introduction}

Recently, downsizing and supercharging have formed state-of-the-art technical trend in sparkignited (SI) engines thanks to its high thermal efficiency and low $\mathrm{CO}_{2}$ emissions. However, an engine knocking combustion is likely to occur under the low-speed and high-load conditions where incylinder temperature and pressure are relatively high, and local stoichiometric fuel/air mixture is prone to an intensive auto-ignition with strong pressure waves or even shock waves [1]. It is generally recognized that conventional knock is caused by end-gas auto-ignition before the arrival of SI flame, and super-knock is attributed to the secondary gaseous auto-ignition followed by a developing detonation wave $[2,3]$. When super-knock occurs, the stochastic auto-ignition may explosively consume the entire mixture within less than a millisecond and induces a knocking intensity beyond 200 bar [4]. Research on knocking combustion is crucially important because it determines engine durability, fuel consumption and engine performance.

In recent literature, there are extensive studies on auto-ignition mode due to its close relevance with knocking intensity [5-8]. A pioneering work by Zel'dovich [9] showed that caused by the nonuniform reactivity of reactive flows, there are different auto- ignition modes (i.e. subsonic deflagration, detonation and super- sonic deflagration). In this classification, thermal explosion represents a limiting case of supersonic auto-ignition with an infinite reaction front speed. Based on a single hot-spot with certain temperature gradient, Bradley and co-workers $[10,11]$ proposed an operational peninsula, which consists of a normalized temperature gradient $(\xi)$ and a ratio of acoustic time to excitation time of chemical energy release $(\varepsilon)$. This peninsula has been widely adopted to classify different combustion regimes with clear regime boundaries in terms of autoignition mode during knocking combustion [12,13]. Later, Chen and co-workers [14] extended above auto-ignition theory to negative temperature coefficient (NTC) region of large hydrocarbon fuels, and found that NTC chemistry does not significantly affect auto-ignition mode for fixed $\xi$ and $\varepsilon$. A recent work by Zhang et al. [15] showed that both thermal and concentration stratifications as well as their cross-coupling can significantly affect the development of auto-ignition mode. Basically, these studies have given great insights into the critical conditions of different auto-ignition modes. In most previous work, however, certain thermal or concentration stratifications are artificially introduced into an initially non-reactive flow, which inevitably neglect the effect of early-stage combustion on subsequent auto-ignition initiation and development during engine knocking combustion.

According to above auto-ignition theory [9-11], auto-ignition mode is closely associated with the thermochemical status of local mixture at auto-ignition moment, including temperature, pressure, equivalence ratio, and reaction progress, etc. During the early stage of engine combustion, the thermochemical status of fuel/air mixture is significantly affected by multi-physical processes, such as turbulence flow [16], pressure wave disturbance [17], flame front compression and radiation [18], etc. Robert et al. [13] conducted 15 LES cycles to study the mechanism of deflagration to detonation in a highly downsized SI engine, and found that pressure wave propagation can be strong enough to induce a significant fresh gases temperature increase leading itself to a substantial decrease of ignition delay time. Liberman et al. $[19,20]$ pointed out that the reflection and intersection of pressure wave in engine cylinder are of crucial importance for local auto-ignition initiation and knocking formation. Furthermore, many optical experiments in engines and rapid compression machines also showed that local explosive auto-ignition at near-wall region is closely associated with 
the pressure wave propagation and reflection under enclosed conditions $[21,22]$. These studies elucidate the significant role of pressure wave disturbance in local auto-ignition initiation and development during knocking combustion. Previous work by Chen et al. [23,24] systematically investigated various auto-ignition modes under different thermodynamic state and chamber length, allowing for the effect of pressure wave disturbance on auto-ignition location. How- ever, the essential role of pressure wave strength in modifying auto-ignition mode and knocking intensity has not been comprehensively studied. In addition, there is little literature involving the effects of flow disturbance on auto-ignition mode and knocking intensity under engine-like conditions.

As a continuous endeavor of previous study $[23,24]$, the primary objective of current work is to further explore the role of pressure wave disturbance in auto-ignition mode and knocking intensity under enclosed conditions. A simplified one-dimensional (1D) constant-volume configuration with well-defined initial and boundary conditions has been adopted, with detailed chemistry and transport of $\mathrm{H}_{2}$ /air mixture. Despite the limitations of current $1 \mathrm{D}$ simulation, it is capable of capturing most of the essential physics and chemistry during knocking combustion, such as flow unsteadiness, local auto-ignition, pressure/shock wave, deflagration and detonation wave with little ambiguity in analysis. Such fundamental research shall give insights into flow disturbance (e.g. pressure wave, turbulence fluctuations, etc.) effect on auto-ignition behavior and knocking combustion under actual engine conditions.

\section{Methodology and numerical model}

\subsection{Methodology}

A time-accurate and space-adaptive numerical solver for Adaptive Simulation of Unsteady Reactive Flows (A-SURF) [25] has been used to resolve the multi-physical combustion involving flame front, pressure wave, local auto-ignition and detonation wave in present work. The in-house A-SURF code accounts for unsteady Navier-Stokes equations and species conservation equation for compressible multi-components reactive mixture using finite volume method. The production rate of intermediate species due to chemical reaction is specified via collection of elementary reactions using a CHEMKIN compatible database [26]. The mixture-averaged method is employed to calculate diffusion velocity, allowing for the Soret diffusion effect of $\mathrm{H}$ and $\mathrm{H}_{2}$. During the simulation, Strang splitting fractionalstep procedure with second-order accuracy has been adopted to separate the time evolution of stiff reaction term from that of convection and diffusion terms. In the first fractional step, non-reactive flow is resolved and second-order Runge-Kutta, MUSCL-Hancock and central difference schemes are employed to calculate temporal integration, convective and diffusion flux, respectively. The second fractional step is to solve chemistry term using VODE solver. Meantime, a multi-level algorithm with adaptive mesh refinement (AMR) has been applied based on the first-order and second-order gradient of temperature, velocity and species distributions to guarantee accurate numerical resolutions for reaction front, local auto-ignition and pressure/shock wave. The finest mesh of $d x=1.0 \mu \mathrm{m}$ and corresponding time step of $\delta t=8 \times 10^{-11} \mathrm{~s}$ have been utilized in present work. A-SURF has been successfully applied to the study of laminar and super-sonic combustion $[27,28]$. The detailed specifications on governing equations and numerical scheme and code validation can be found in [27-29], and thus are not repeated here. 


\subsection{Numerical model}

A 1D planar constant-volume reactor is modeled to represent the combustion chamber of SI engine when piston is located at the Top Dead Center. To reduce computation expenses, symmetric boundary condition is adopted at reactor centerline, such that the entire computation domain size, corresponding to the cylinder bore of a general downsizing $\mathrm{SI}$ engine, is reduced from $L=8.0 \mathrm{~cm}$ to $4.0 \mathrm{~cm}$. Adiabatic and reflective boundary conditions are adopted at end wall. Initially a $2.0 \mathrm{~mm}$ thick hot ignition kernel denoted by $T_{h}$ is artificially created as the spark ignition kernel surrounded by quiescent homogeneous stoichiometric $\mathrm{H}_{2}$ /air mixture. The initial temperature of unburned mixture outside of hot ignition kernel, ranging from $T_{0}=700 \mathrm{~K}$ to $1100 \mathrm{~K}$, is emphatically investigated at initial pressure of $P_{0}=5 \mathrm{~atm}$. Besides, the same combustion scenarios are also evaluated at elevated pressure of $P_{0}=10 \mathrm{~atm}$ and shall be discussed later. In previous work [23], ignition temperature of the hot ignition kernel is fixed to $T_{h}=1500 \mathrm{~K}$, which is close to the minimum ignition temperature [30]. However, it is found that numerical results depend on not only the initial temperature of unburned mixture, but also the ignition temperature of hot ignition kernel. In present work, the ignition temperature has been varied from $T_{h}=1500 \mathrm{~K}$ to corresponding equilibrium temperature $\left(T_{E}\right)$ of each initial temperature, which corresponds to an energy deposition of $Q_{E}=7-20 \mathrm{~mJ}$ required to heat-up the mixture to these temperatures at initial pressure of $P_{0}=5 \mathrm{~atm}$ conditions. Such a way can produce a pressure wave with different levels in strength propagating back-and-forth in constant-volume reactor. Depending on the evolutions of thermochemical status of unburned mixture, local auto-ignition may occur somewhere with appropriate conditions. The schematic of constant-volume reactor with initial and boundary conditions can be found in Figure 1.

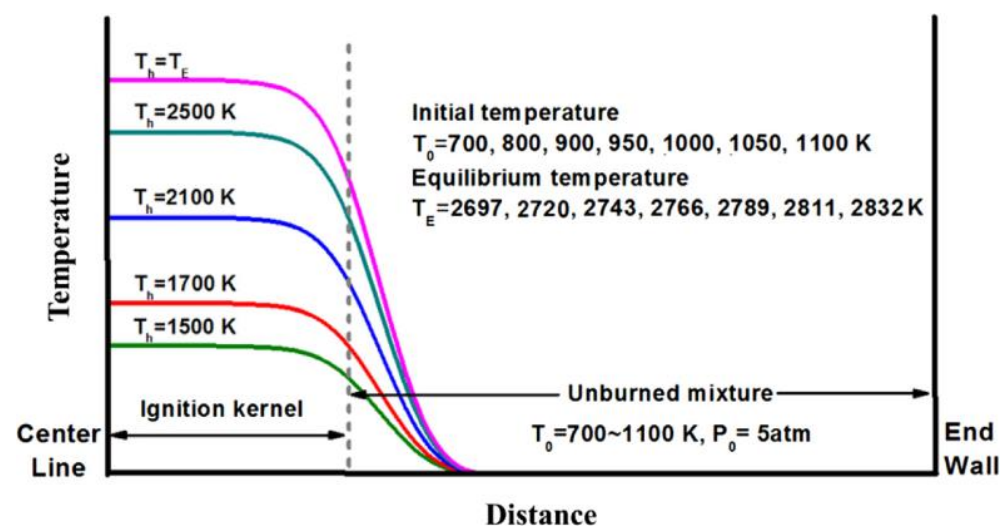

Figure 1 Schematic of the constant-volume reactor with initial and boundary conditions.

The chemical kinetic mechanism adopted here is an updated comprehensive $\mathrm{H}_{2}$ /air kinetic model suitable for high-pressure combustion [31]. This detailed mechanism has been tested against a wide range of combustion targets including high-pressure flame speed, with updated rate constants. It should be noted that current work is mainly to understand laminar combustion regime, so turbulence effect is not considered here. Such a simplified configuration is still able to provide insights into the fundamentals of physical and chemical elements of actual combustion system.

\section{Results and discussions}




\subsection{Generation of pressure wave disturbance}

Generally, a pressure wave is formed during flame build-up and decay as well as when flame front propagates into a medium with different physicochemical properties. For a local hot-spot, it is inherently unstable at high temperature because the exponential increases of heat release rate tend to induce thermal runaway and localized explosion. Such that a pressure wave (and even shock wave) will be generated and then move outwards with local sound speed [30]. Figure 2 shows the evolutions of a pressure wave initiated from hot ignition kernel at $T_{h}=1500 \mathrm{~K}$ for $T_{0}=900 \mathrm{~K}$ case. It is observed that during SI flame formation at the region of $x=0.0-0.1 \mathrm{~cm}$, a pressure wave quickly develops and then detaches from the SI flame front. At this moment, laminar flame speed is approximately $v=40 \mathrm{~m} / \mathrm{s}$ and pressure wave velocity is $a=713 \mathrm{~m} / \mathrm{s}$. Due to the pressure wave disturbance, there is an obvious increase in the temperature and pressure of local mixture, with $\Delta T=60 \mathrm{~K}$ and $\Delta P=1.5 \mathrm{~atm}$, respectively. It should be noted that different from the strong pressure wave or shock wave induced by intensive auto-ignition during knocking combustion as discussed later, the auto-ignition at hot ignition kernel is mild and pressure wave strength is relatively weak.
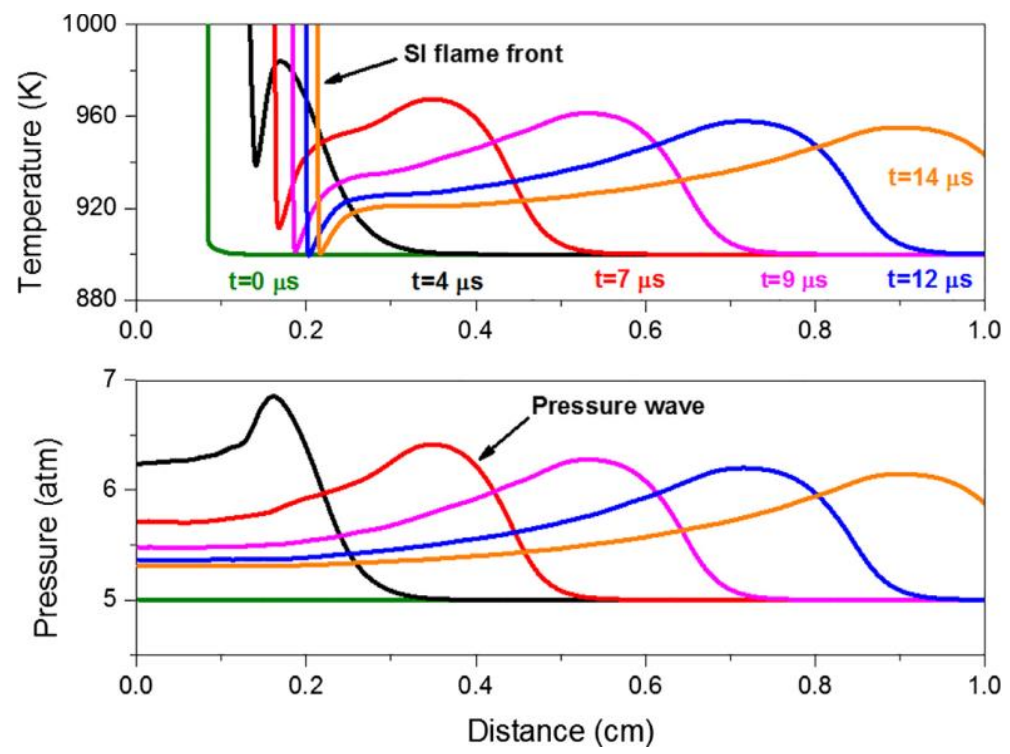

Figure 2 Evolutions of the pressure wave from hot ignition kernel with ignition temperature of $T_{h}=1500 \mathrm{~K}$ for $T_{0}=900 \mathrm{~K}$ case.

To obtain the characteristics of pressure wave generated from hot ignition kernel, direct numerical simulations with full chemical kinetics and momentum equation have been performed at different operation conditions. Figure $\mathbf{3}$ shows the results of compression ratio and temperature rise caused by pressure wave disturbance at the early stage of combustion (i.e. $t=0-14 \mu \mathrm{s}$ ). Here the compression ratio is defined as the ratio of pressure peak $\left(P_{\max }\right)$ to initial pressure $\left(P_{0}\right)$, which represents the strength of a pressure wave. It is observed that pressure wave strength can be obtained through adjusting initial temperature and ignition temperature while keeping initial pressure constant. Under the same initial temperature conditions, both compression ratio and temperature rise caused by pressure wave disturbance decrease as ignition temperature is raised, e.g. the temperature rise decreases from $\Delta T=60 \mathrm{~K}$ at $T_{h}=1500 \mathrm{~K}$ to from $\Delta T=18 \mathrm{~K}$ at $T_{h}=2743 \mathrm{~K}$. This is because pressure wave strength mainly depends on the volumetric heat release of hot ignition kernel, and as the increases of ignition temperature, the energy density of hot ignition 
kernel is significantly reduced for given initial pressure [32]. Moreover, it is observed that under the same ignition temperature conditions, there is an increase in temperature rise as initial temperature is raised while compression ratio is kept almost constant. This indicates that compression ratio (i.e. pressure wave strength) mainly depends on the ignition temperature of hot ignition kernel, and temperature rise is determined by both initial temperature and ignition temperature. These pressure waves with different levels in strength will play a significant role in subsequent flame propagation, local auto-ignition and knocking combustion as discussed later.

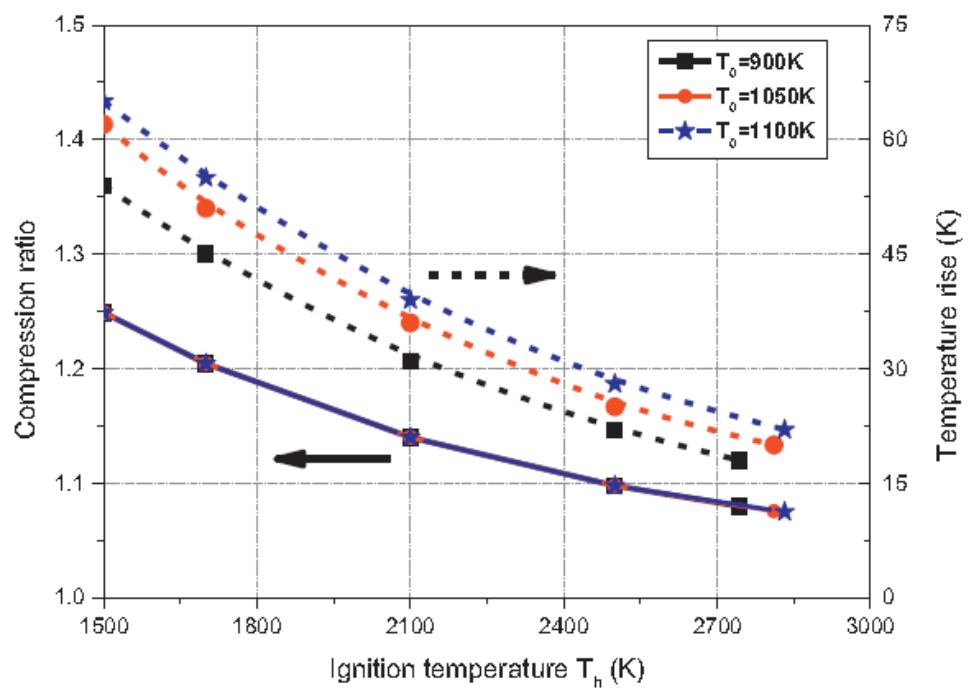

Figure 3 Compression ratio and temperature rise caused by pressure wave disturbance at different ignition temperatures and initial temperatures.

To demonstrate the effect of pressure wave disturbance on combustion process, Figure 4 firstly shows the evolutions of flame speed and heat release rate as well as the thermodynamic state of end-gas mixture $(x=4.0 \mathrm{~cm})$ at initial temperature of $T_{0}=900 \mathrm{~K}$. 


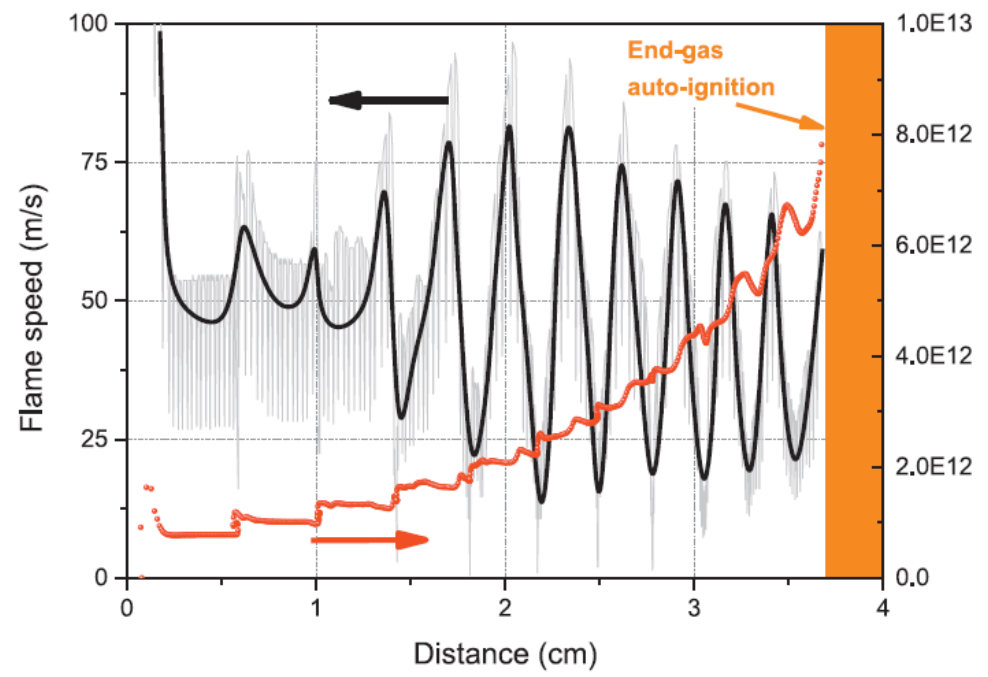

(a)

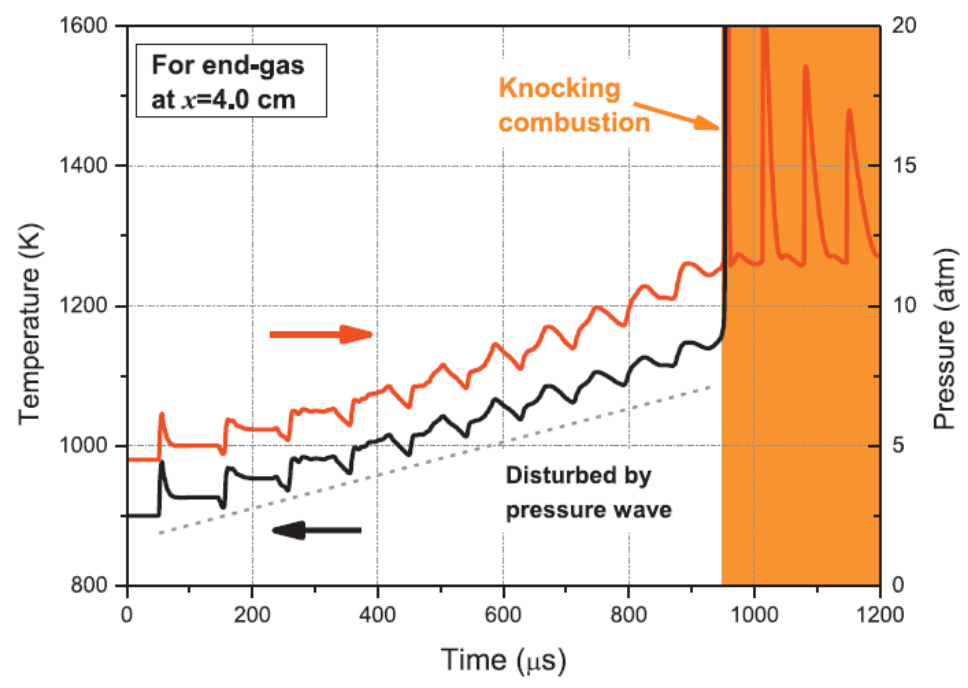

(b)

Figure 4 Evolutions of (a) flame speed and heat release rate and (b) temperature and pressure of end-gas mixture with pressure wave disturbance at $T_{0}=900 \mathrm{~K}$.

It is observed from Figure $\mathbf{4}$ (a) that during SI flame propagation, transient flame speed shows an unsteady behavior with instantaneous high-frequency fluctuations due to combustion instabilities. With pressure wave disturbance to flame front, there is also an obvious macroscale fluctuation in the mean flame speed with a level of $v=45 \mathrm{~m} / \mathrm{s}$. Meanwhile, it is noted that the improvement in fresh temperature and pressure promotes the increases in heat release rate of flame front as a consequence of burned gas expansion and pressure wave disturbance. Figure $\mathbf{4}$ (b) shows that due to the reflection of pressure wave at end wall $(x=4.0 \mathrm{~cm})$, end-gas pressure and temperature increase non-smoothly, which then promote the accumulations of end-gas mixture reactivity. Depending on the progress of chemical reaction, an auto-ignition event may occur somewhere when it reaches a critical condition (e.g. $t=952 \mu$ s).

\subsection{Auto-ignition mode and knocking intensity}

Numerical simulations involving knocking and non-knocking cases at different initial temperatures and ignition temperatures have been conducted in current work. But here we just present the 
results of three typical knocking cases with initial temperature of $T_{0}=900,1050$ and $1100 \mathrm{~K}$, respectively. This is because previous work [23] shows that when initial temperature is below $T_{0}=900 \mathrm{~K}$, there is no local auto-ignition event and normal combustion proceeds. Once initial temperature reaches $T_{0}=900 \mathrm{~K}$, an auto-ignition starts to take place at end-wall region, as shown in Figure $\mathbf{5}$ (a). As initial temperature is raised up to $T_{0}=1050 \mathrm{~K}$, local auto-ignition occurs not only at end-wall region, but also at the location ahead of $\mathrm{SI}$ flame front. Further increases in initial temperature to $T_{0}=1100 \mathrm{~K}$, auto-ignition only occurs at the location ahead of SI flame front. Therefore, as the increases of initial temperature, there is a transition in auto-ignition location from near-wall region to the location ahead of SI flame front, as shown in Figure $\mathbf{5}$ (b).

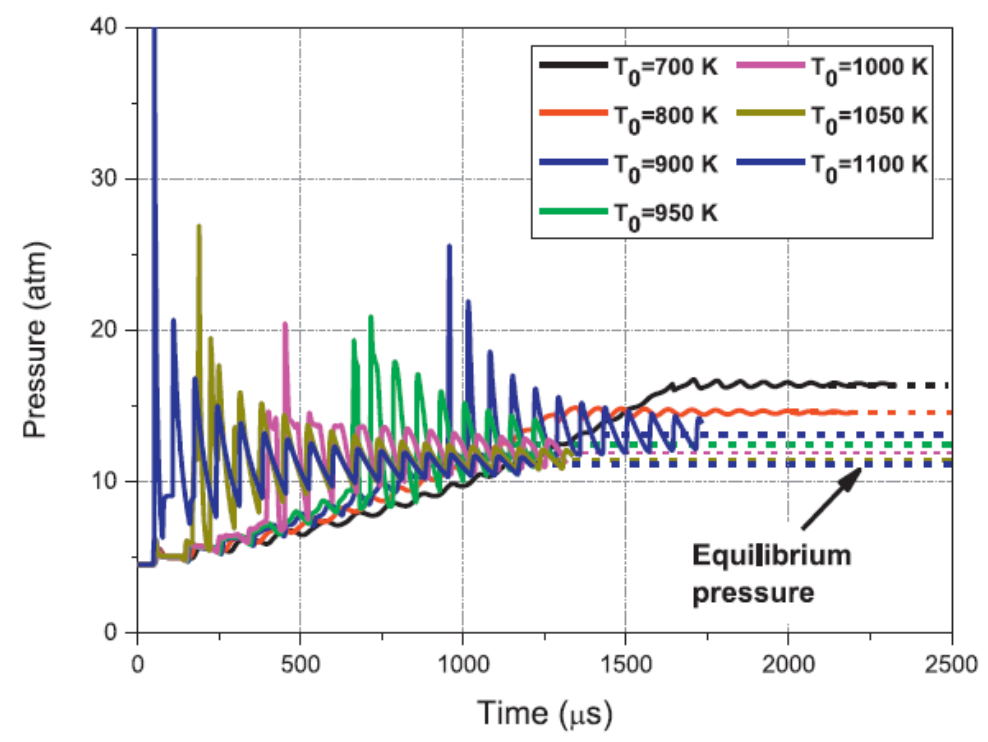

(a)
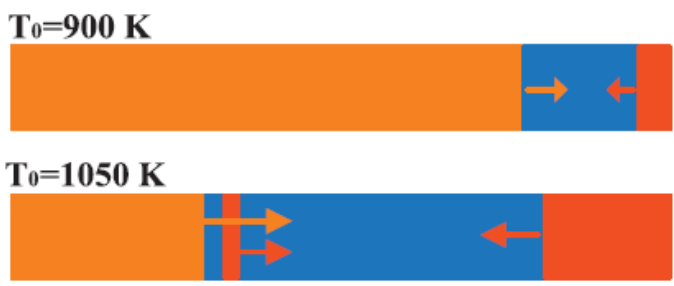

$\mathrm{T}_{0}=1100 \mathrm{~K}$

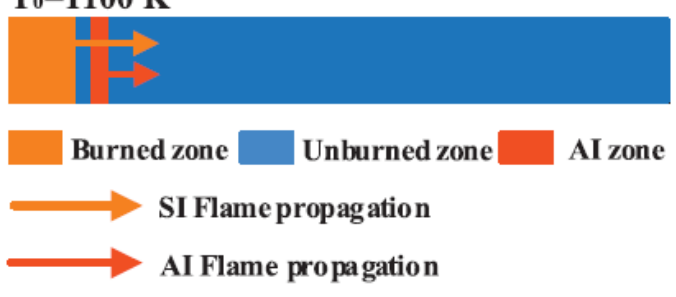

(b)

Figure 5 (a) Pressure history of end-gas mixture and (b) scenarios of local auto- ignition and flame propagation at different initial temperatures for $T_{h}=1500 \mathrm{~K}$ [23].

Figure 6 shows the temporal consequences of temperature, pressure and heat release rate at $T_{0}=900 \mathrm{~K}$ for ignition temperature of $T_{h}=1500$ and $2743 \mathrm{~K}$. It is observed from Figure 6 (a) that when $t=953.08 \mu \mathrm{s}$, an auto-ignition event occurs at end-wall region, but subsequent auto-ignition (AI) reaction front does not directly develop into a detonation wave, which is characterized by the 
limited peak of pressure and heat release rate. After the first auto-ignition event, pressure wave propagation increases local temperature and pressure and leads to a substantial decrease in ignition delay time of unburned mixture ahead of Al reaction front. Such that a second auto-ignition event quickly takes place at the location ahead of Al reaction front at $t=955.47 \mu \mathrm{s}$. Subsequently, the Al reaction front quickly develops into a detonation wave with a velocity of $v=1950 \mathrm{~m} / \mathrm{s}$, closing to the C-J detonation speed of $v_{C J}=1955 \mathrm{~m} / \mathrm{s}$ for stoichiometric $\mathrm{H}_{2}$ /air mixture at $T=1222 \mathrm{~K}$ and $P=12.74 \mathrm{~atm}$. Meanwhile, the peak of pressure and heat release rate reaches $P_{\max }=89 \mathrm{~atm}$ and $Q_{\max }=10^{15} \mathrm{~J} / \mathrm{m}^{3} \mathrm{~s}$, respectively. When ignition temperature is raised up to $T_{h}=2743 \mathrm{~K}$, it becomes totally different for the structure of Al reaction front, even though there is no variations in auto-ignition location, as shown in Figure 6 (b). After the end-gas auto-ignition at $t=977.00 \mu \mathrm{s}$, the Al reaction front induced tends to develop towards a detonation wave. However, it becomes dominant for the partial reaction of unburned mixture ahead of Al reaction front at the same time. As a consequence, end-gas mixture seems consumed by a mixed auto-ignition mode with complex reaction front structure.

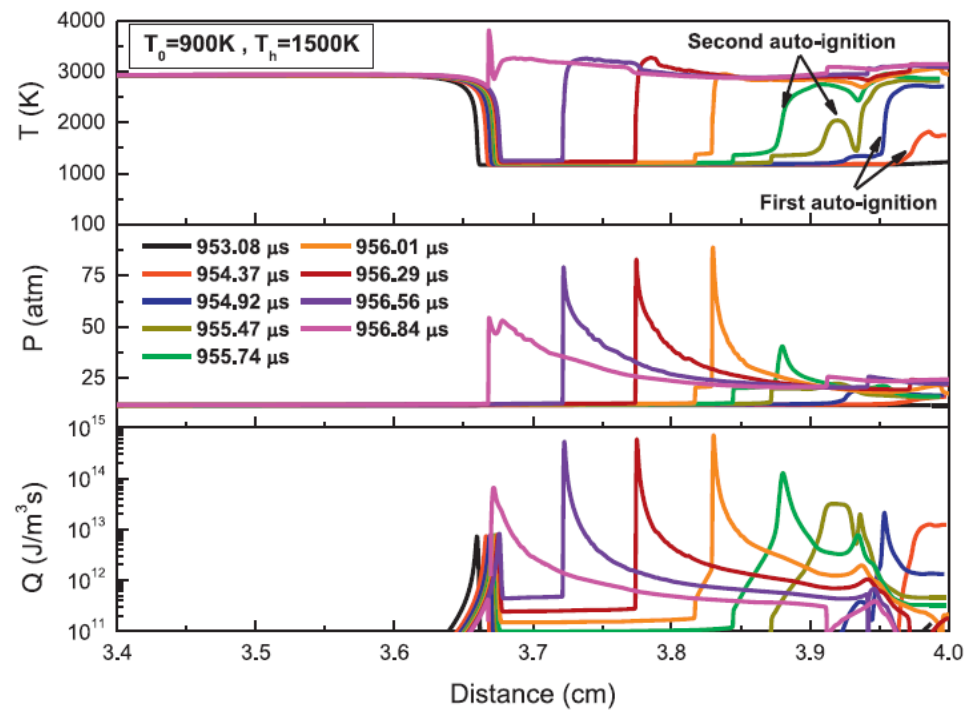

(a)

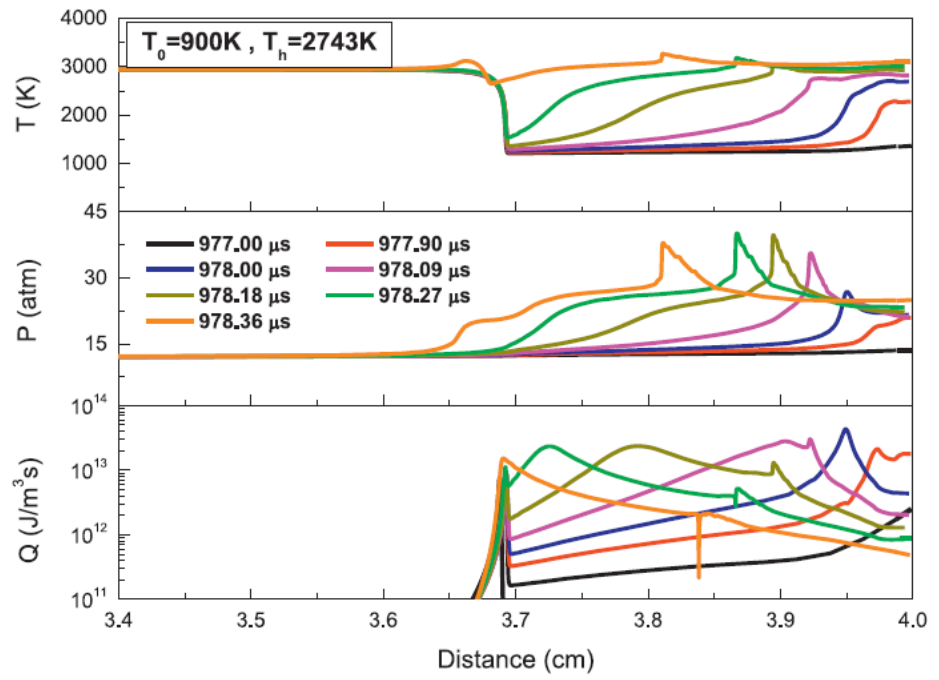

(b)

Figure 6 Temporal sequences of temperature $(T)$, pressure $(P)$ and heat release rate $(Q)$ at $T_{0}=900 \mathrm{~K}$ for (a) $T_{h}=1500 \mathrm{~K}$, and (b) $T_{h}=2743 \mathrm{~K}$. 
Figure 7 shows the results of initial temperature of $T_{0}=1050 \mathrm{~K}$ case. It is observed that similar to previous work [23], local auto-ignition takes place not only at near-wall region, but also at the location ahead of SI flame front. Although pressure wave disturbance does not modify auto-ignition location and knocking origin; however, there is an obvious variation in Al reaction front structure as the increases of ignition temperature (i.e. the decreases of pressure wave strength). For $T_{h}=$ $1500 \mathrm{~K}$ case, there is distinct discontinuity in temperature and pressure traces and sufficiently high pressure amplitude in terms of Al reaction front, manifesting the characteristics of a detonation wave. While when $T_{h}=2100 \mathrm{~K}$, the entire Al reaction front consists of a detonation wave and a partial-reaction zone, which is recognized as the mixed auto-ignition mode in current work. Further increases in ignition temperature to $T_{h}=2811 \mathrm{~K}$, detonation wave disappears and flame thickness becomes very large, suggesting the auto-ignition event has completely transited into another new combustion regime.

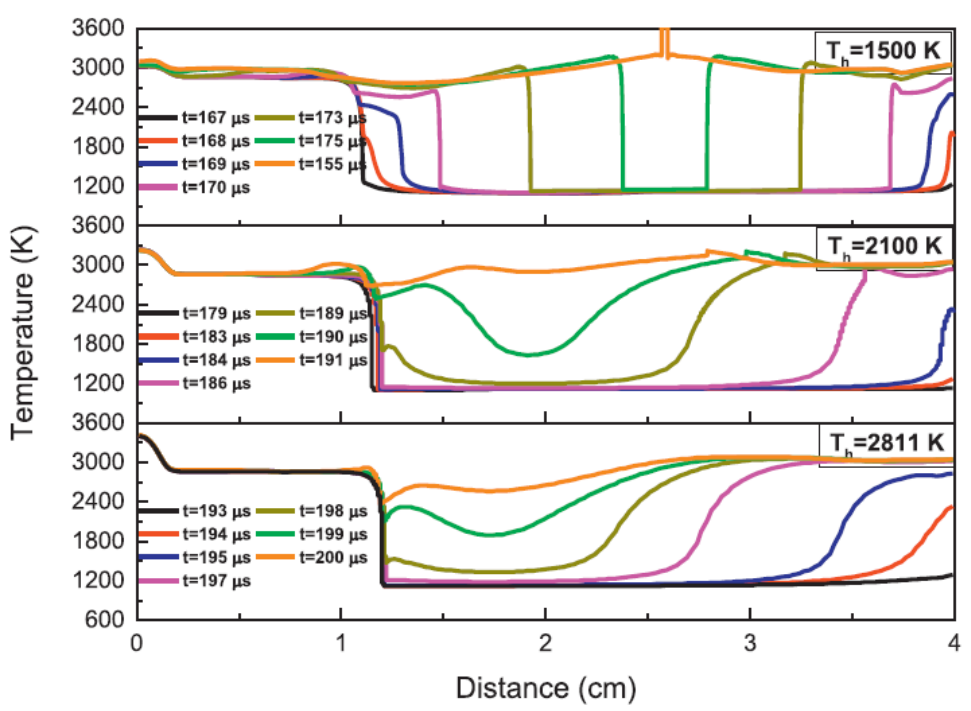

(a)

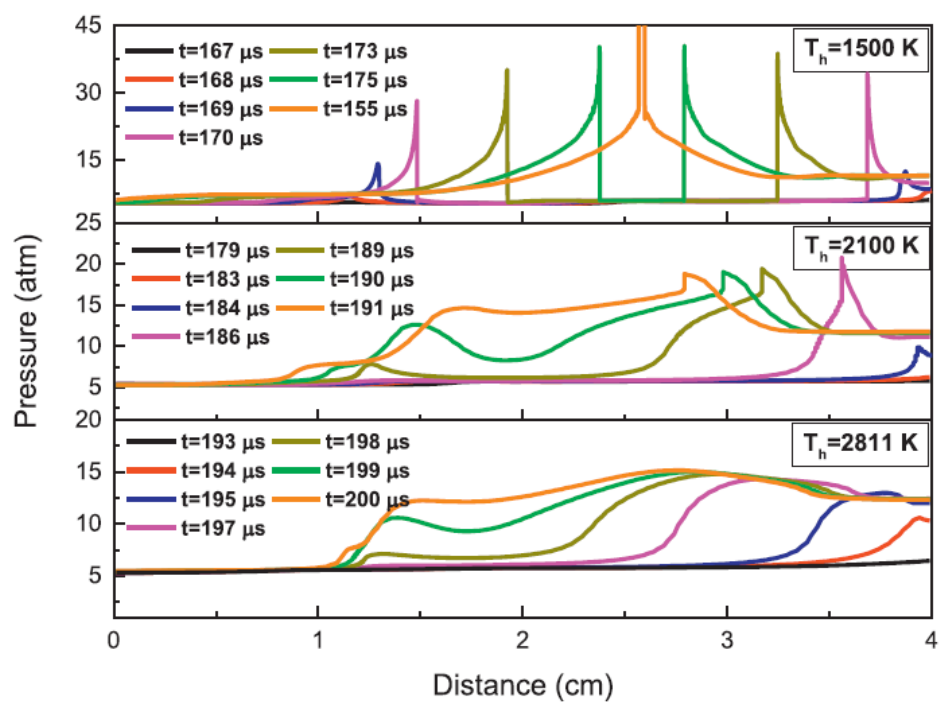

(b)

Figure 7 Temporal sequences of (a) temperature and (b) pressure at $T_{0}=1050 \mathrm{~K}$ for different ignition temperatures. 
To further validate above conclusion, Figure 8 gives the results of Al reaction front speed at different ignition temperatures for $T_{0}=1050 \mathrm{~K}$ case. Here Al reaction front is identified through maximum heat release rate of local mixture, and corresponding propagation speed of Al reaction front is defined as the rate of change in the location within unit time. It is observed that after end-gas autoignition, the propagation speed of Al reaction front for both $T_{h}=1500$ and $2100 \mathrm{~K}$ cases increases from the subsonic to supersonic level. Therefore, there is a possibility that Al reaction front and pressure wave interacts each other for the cases of $T_{h}=1500$ and $2100 \mathrm{~K}$, rather than the $T_{h}=2811 \mathrm{~K}$ case where Al reaction front speed is always far beyond local sound speed. Specifically, the Al reaction front speed of $T_{h}=1500 \mathrm{~K}$ case increases from subsonic level to approximately $v=1800 \mathrm{~m} / \mathrm{s}$, closing to the C-J detonation speed at corresponding thermodynamic state. Because of the pre-flame partial reactions at $T_{h}=2100 \mathrm{~K}$, Al reaction front has a propagation speed of $v=3600 \mathrm{~m} / \mathrm{s}$, which is beyond C-J detonation speed at $x=3.0 \mathrm{~cm}$. These observations again demonstrate that there is a mode transition for end-gas auto-ignition with the decreases in strength of pressure wave disturbance.

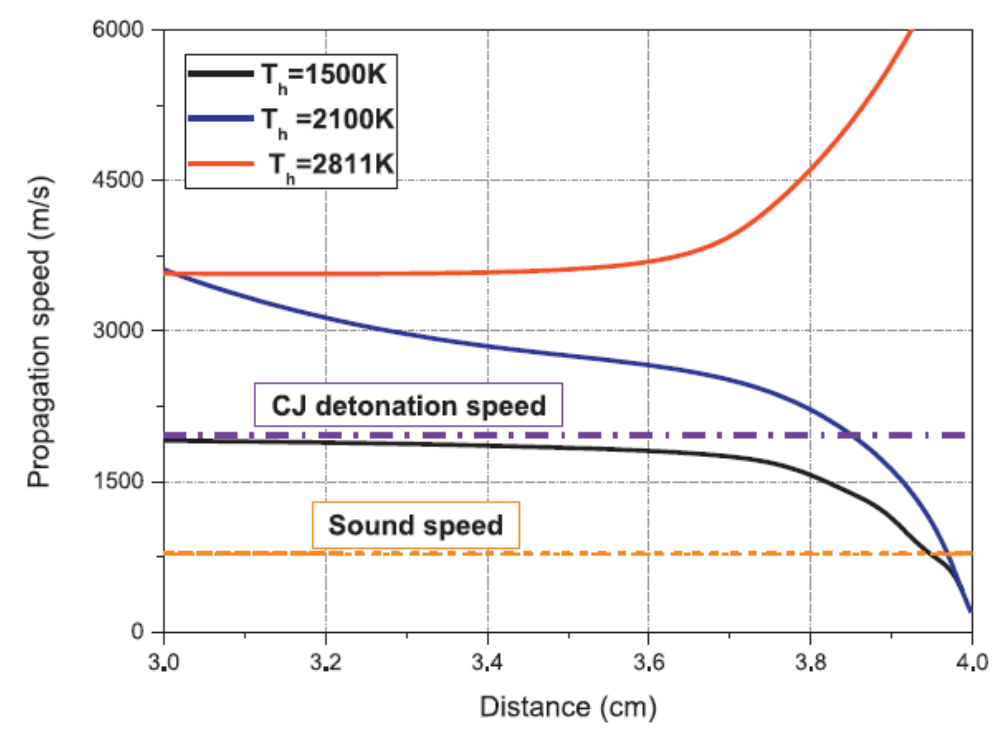

Figure 8 Auto-ignition reaction front speed of different ignition temperatures for $T_{0}=1050 \mathrm{~K}$ end-wall auto-ignition, with sound speed and C-J detonation speed for comparisons.

Figure 9 shows the results of temperature, pressure, and heat release rate at $T_{0}=1100 \mathrm{~K}$ case where local auto-ignition takes place only at the location ahead of SI flame front. Similar to the scenarios of end-gas auto-ignition at $T_{0}=900$ and $1050 \mathrm{~K}$, auto-ignition mode transition is still observed even though the auto-ignition event is located ahead of $\mathrm{SI}$ flame front. As ignition temperature is raised from $T_{h}=1500$ to $2843 \mathrm{~K}$ (with decreasing pressure wave strength), the peak of pressure (and heat-release rate) for Al reaction front decreases from $P_{\max }=30-15 \mathrm{~atm}$ (and from $Q_{\max }=10^{14}$ to $10^{12} \mathrm{~J} / \mathrm{m}^{3} \mathrm{~s}$ ), accompanied by obvious variations in the structure of reaction front. 


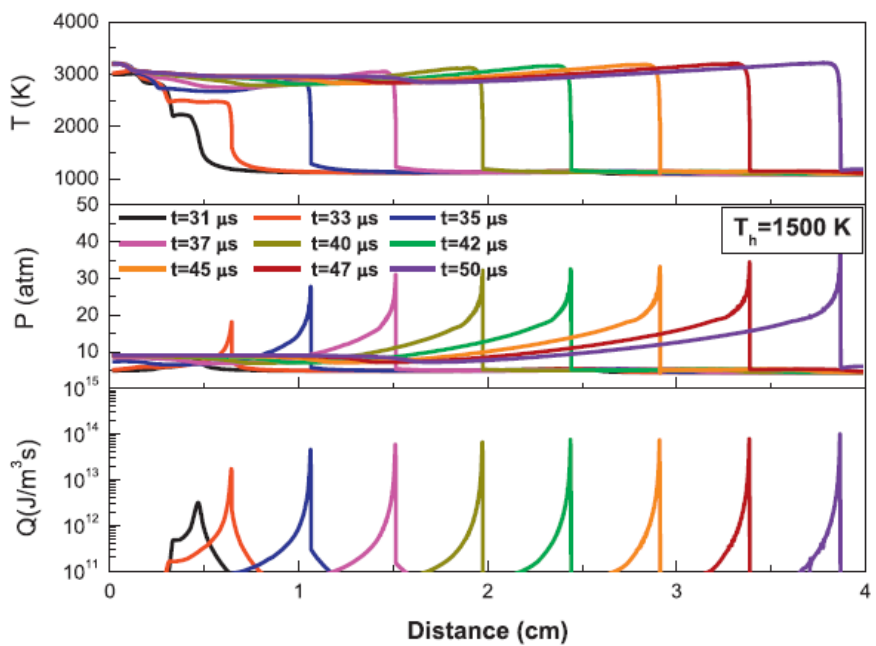

(a)

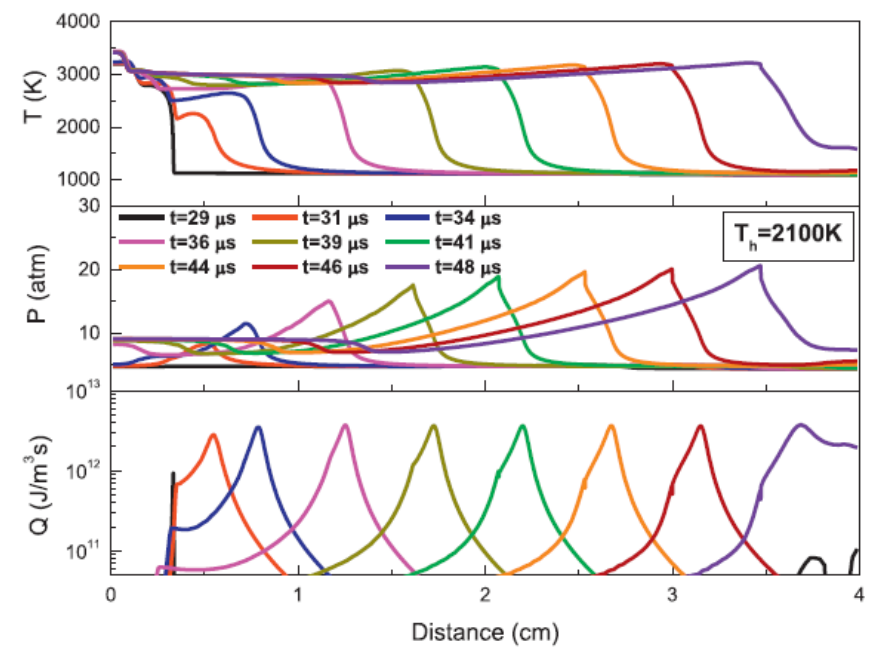

(b)

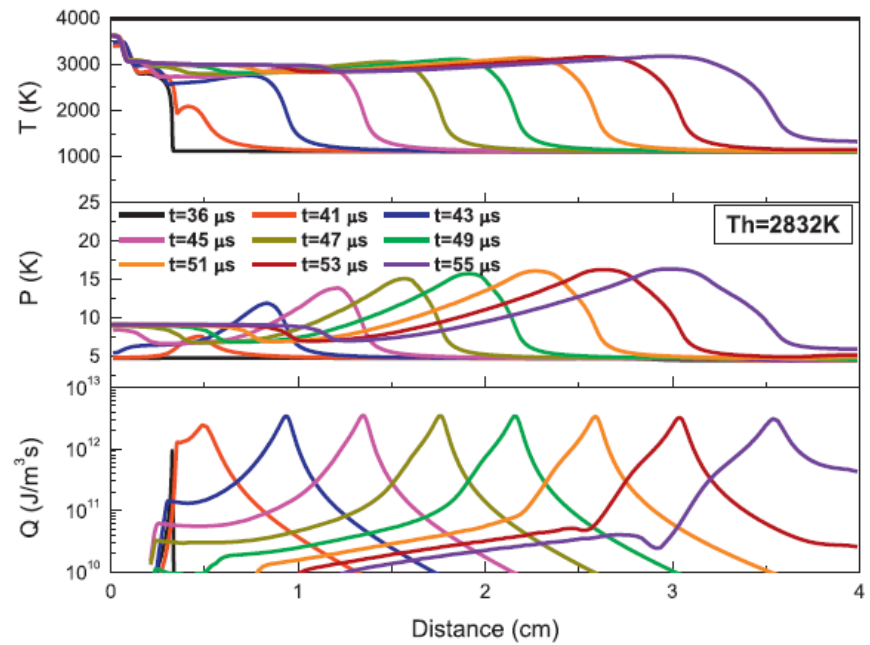

(c)

Figure 9 Temporal sequences of temperature $(T)$, pressure $(P)$ and heat release rate $(Q)$ at $T_{0}=1100 \mathrm{~K}$ for (a) $T_{h}=1500 \mathrm{~K}$, (b) $T_{h}=2100 \mathrm{~K}$ and (c) $T_{h}=2843 \mathrm{~K}$. 
The Al reaction front speed of different ignition temperatures for $T_{0}=1100 \mathrm{~K}$ case is shown in Figure 10. It is observed that after an auto-ignition event at the location ahead of SI flame front, the Al reaction front of $T_{h}=1500 \mathrm{~K}$ case quickly develops into a detonation wave with a propagation speed of $v=1900 \mathrm{~m} / \mathrm{s}$, very closing to the C-J detonation speed of corresponding thermodynamic state. While for $T_{h}=2100$ and $2843 \mathrm{~K}$ cases, the propagation speed of Al reaction front is beyond the C-J detonation speed and behaves the characteristics of a supersonic deflagration. Combined with the results of Figures $\mathbf{8}$ and $\mathbf{1 0}$, it is concluded that as the increases of ignition temperature (i.e. the decreases of pressure wave strength in disturbance), the propagation speed of Al reaction front increases from the level below C-J detonation speed (but far higher than local sound speed) to that of beyond C-J detonation speed. Possible reasons are ascribed to that with the transition of autoignition mode from detonation to supersonic deflagration, pre-flame partial reaction becomes dominant and lots of reactive species significantly reduce ignition delay time of unburned mixture and promote the propagation of Al reaction front.

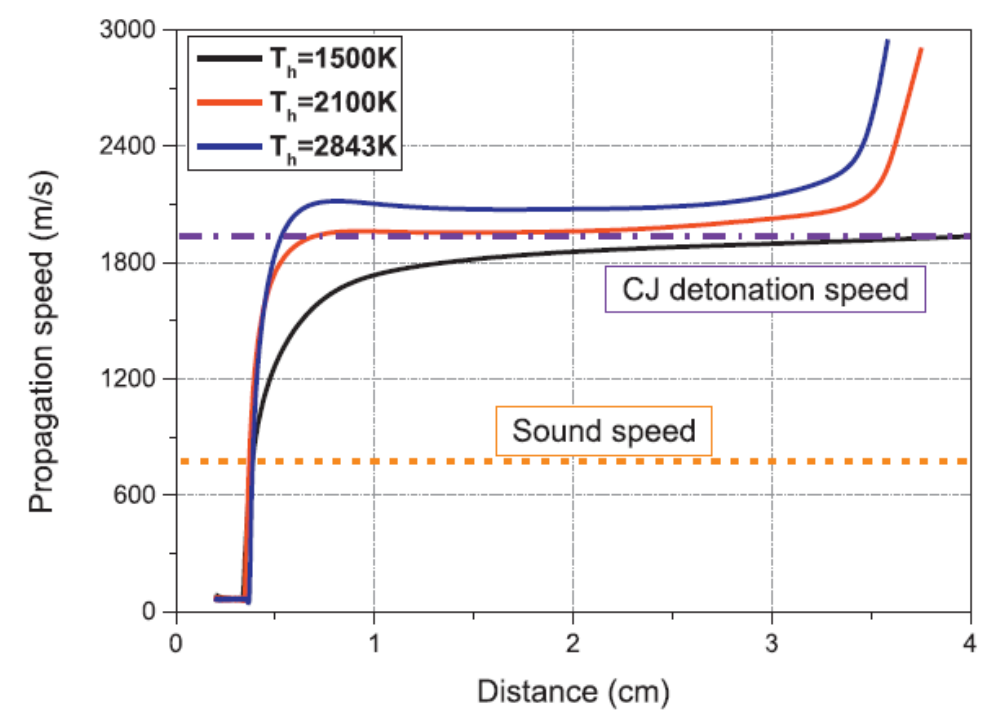

Figure 10 Auto-ignition reaction front speed of different ignition temperatures for $T_{0}=1100 \mathrm{~K}$ pre-flame auto-ignition, with sound speed and C-J detonation speed for comparisons.

\subsection{Mixture status at auto-ignition moment}

To identify the underlying reasons for auto-ignition mode transition, Figure $\mathbf{1 1}$ shows the evolutions of temperature and pressure of end-gas mixture at near-wall region for $T_{0}=1050 \mathrm{~K}$ case. It is observed that after the first-time reflection of pressure wave at end-wall, end-gas mixture temperature and pressure traces return back to the same level for different ignition temperatures (e.g. at $t=100 \mu \mathrm{s}$ ). However, end-gas mixture begins to auto-ignite due to the increases of temperature and pressure after the second-time reflection of pressure wave. Compared with $T_{h}=2100$ and $2811 \mathrm{~K}$ cases, the auto-ignition timing is earlier at $T_{h}=1500 \mathrm{~K}$ because it is disturbed by a stronger pressure wave. 

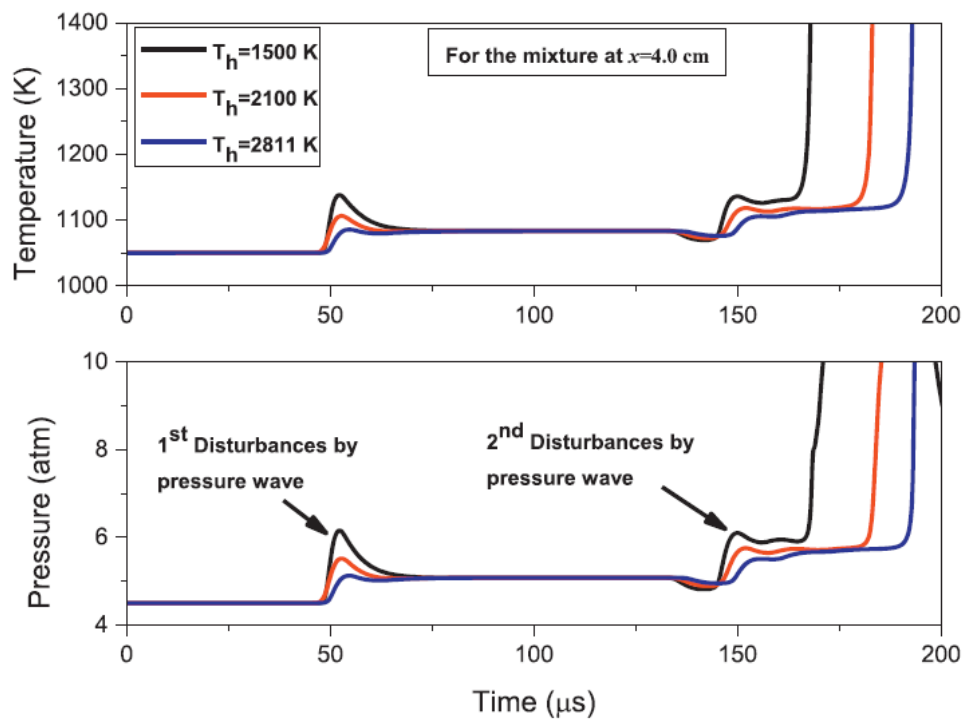

Figure 11 Evolutions of temperature and pressure of end-gas mixture at $T_{0}=1050 \mathrm{~K}$ for different ignition temperatures.

To further understand auto-ignition initiation and development, it is necessary to quantify the thermochemical status of local mixture. Noting that local mixture is always disturbed by a pressure wave propagation in current constant-volume reactor, temperature distribution may not be appropriate for determining mixture reactivity at auto-ignition moment. Therefore, $\mathrm{OH}$ mass fraction $\left(Y_{\mathrm{OH}}\right)$ is adopted here to represent local mixture reactivity, and the instant when $Y_{\mathrm{OH}}=10^{-5}$ is regarded as auto-ignition moment. This definition is well consistent with the calculation results by Lutz et al. [33], and the heat release rate at auto-ignition moment is below $0.1 \%$ of the maximum heat release rate in this work. Figure 12 shows the distributions of temperature and $\mathrm{OH}$ mass fraction in $x=3.0-4.0 \mathrm{~cm}$ region at auto-ignition moment. It is observed that, compared with temperature trace, the distribution of $\mathrm{OH}$ mass fraction gives more clear variation tendency in terms of unburned mixture reactivity. As the increases of ignition temperature (i.e. the decreases of pressure wave strength), mixture reactivity gradient shows a declining trend. Combined with previous results, it can be obtained that the modification in auto-ignition mode caused by pressure wave disturbance is mainly attributed to the variations of mixture reactivity. 

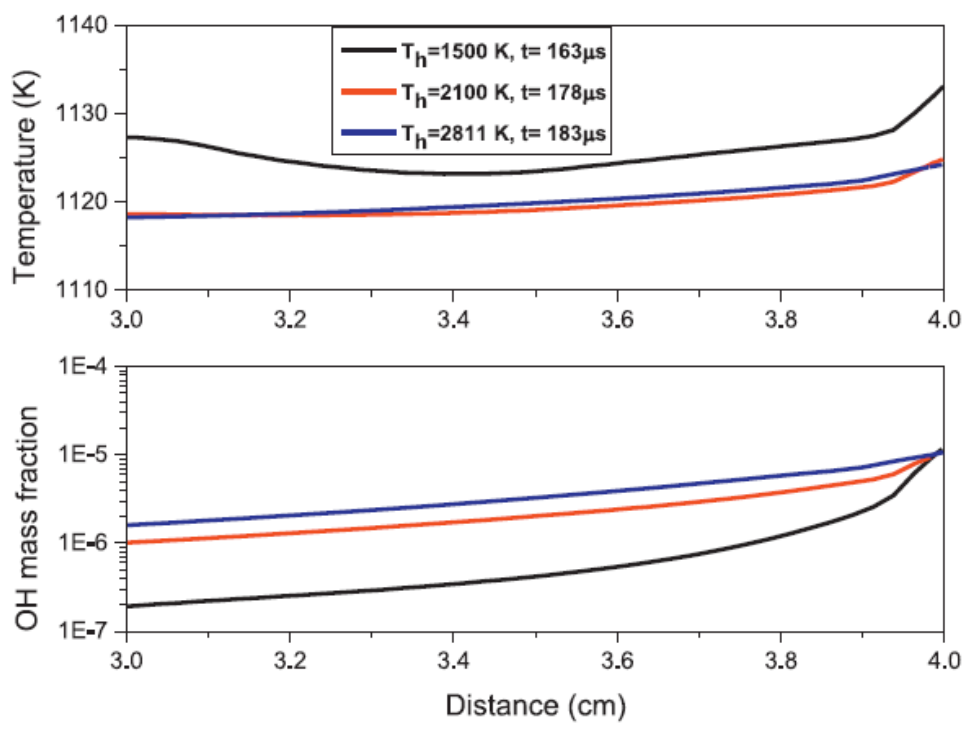

Figure 12 Temperature and $\mathrm{OH}$ mass fraction of end-gas mixture at auto-ignition moment for $T_{0}=1050 \mathrm{~K}$ case.

Figure 13 further gives the evolutions of temperature and pressure for the auto-ignition ahead of $\mathrm{SI}$ flame front at $T_{0}=1100 \mathrm{~K}$. Still, the pressure wave disturbance from initial hot ignition kernel induces obvious increases in the mixture temperature and pressure in preheat zone of SI flame front. At very high initial temperature, pre-flame mixture is almost on the status of auto-ignition threshold, so the improvement of thermodynamic state significantly reduce ignition delay time of adjacent mixture, leading to the pre-flame auto-ignition event. Figure 14 shows the distributions of temperature and $\mathrm{OH}$ mass fraction of pre-flame mixture at auto-ignition moment for $T_{0}=1100 \mathrm{~K}$ case. It is observed that more clear distinctions in mixture reactivity are shown by $\mathrm{OH}$ mass fraction, which again suggests the role of pressure wave disturbance in modifying local mixture reactivity. Meanwhile, these observations also indicate that in actual reactive flows with transient disturbance (e.g. pressure wave or turbulence fluctuations), temperature and pressure may not be efficient for accurately estimating the reactivity distributions of local mixture.

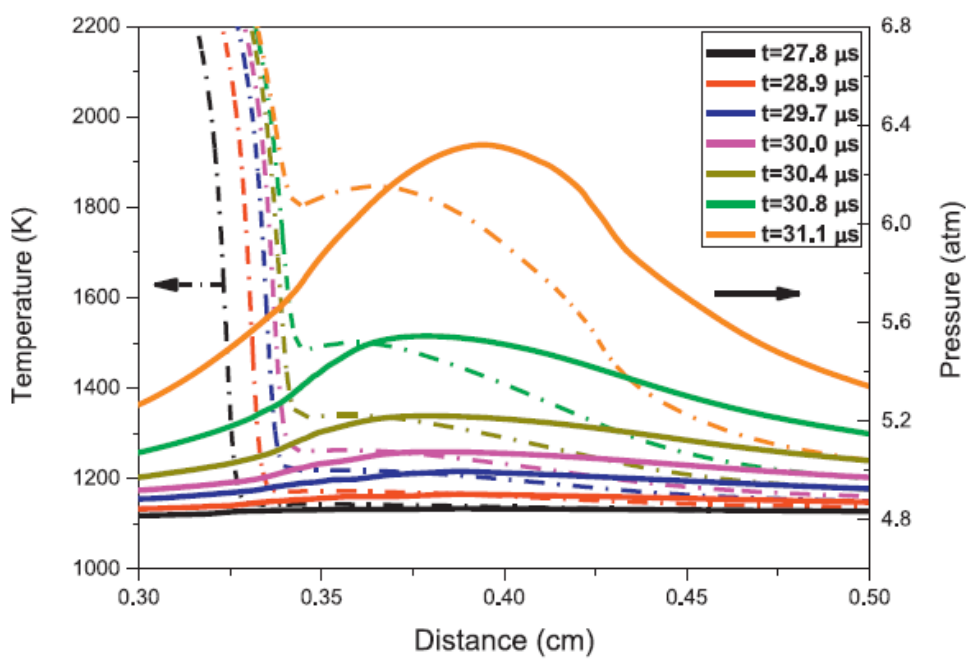

Figure 13 Temperature and pressure of pre-flame mixture ahead of SI flame front at $T_{h}=1500 \mathrm{~K}$ for $T_{0}=1100 \mathrm{~K}$ case. 

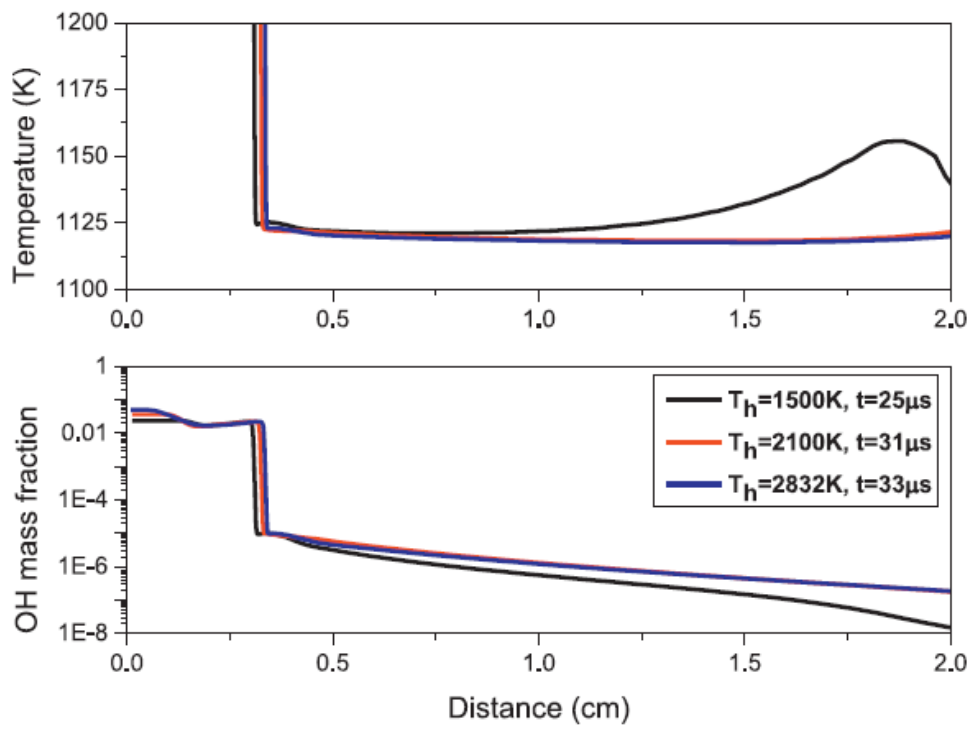

Figure 14 Temperature and $\mathrm{OH}$ mass fraction of pre-flame mixture at auto-ignition moment for $T_{0}=1100 \mathrm{~K}$ case.

\subsection{Auto-ignition scenarios at higher pressure}

To illustrate the effect of ambient pressure on auto-ignition mode and knocking combustion, Figure 15 further shows the temporal sequences of temperature and pressure at initial temperature of $T_{0}=1050 \mathrm{~K}$ and elevated initial pressure of $P_{0}=10 \mathrm{~atm}$. It is observed from Figure 15 (a) that similar to the cases with lower initial pressure, auto-ignition events occur at both end-wall region and pre-flame location for all ignition temperature cases at $T_{0}=1050 \mathrm{~K}$. As the ignition temperature increases (i.e. decreases of pressure wave strength), auto-ignition timing is retarded, and partial reaction becomes obvious at the location ahead of Al reaction front. This indicates that the variations of auto-ignition mode caused by pressure wave disturbance are still maintained at elevated initial pressure. 


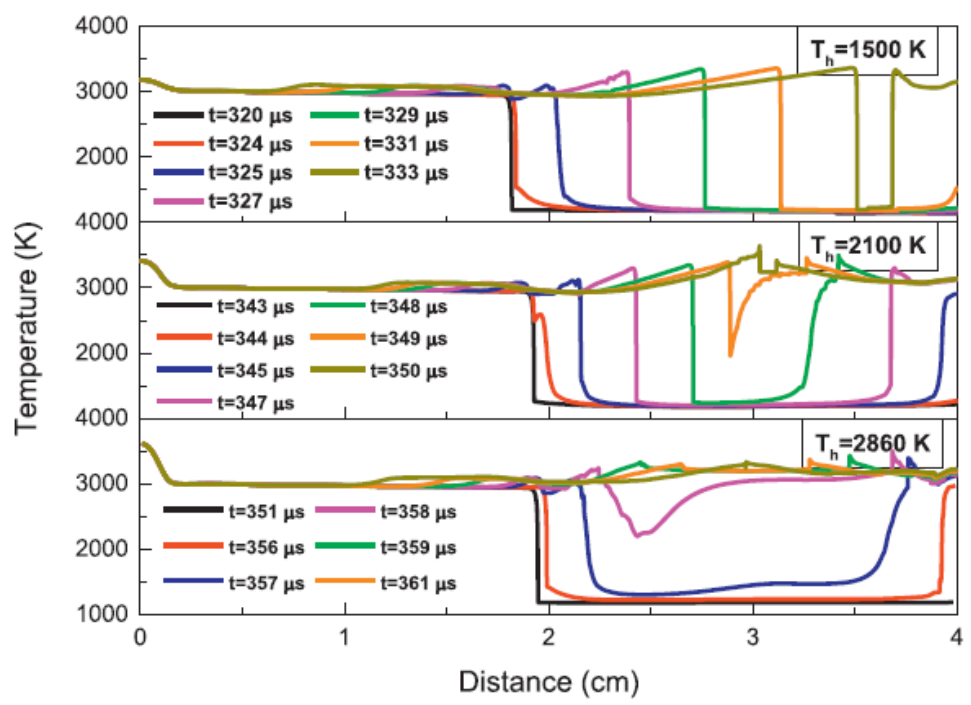

(a)

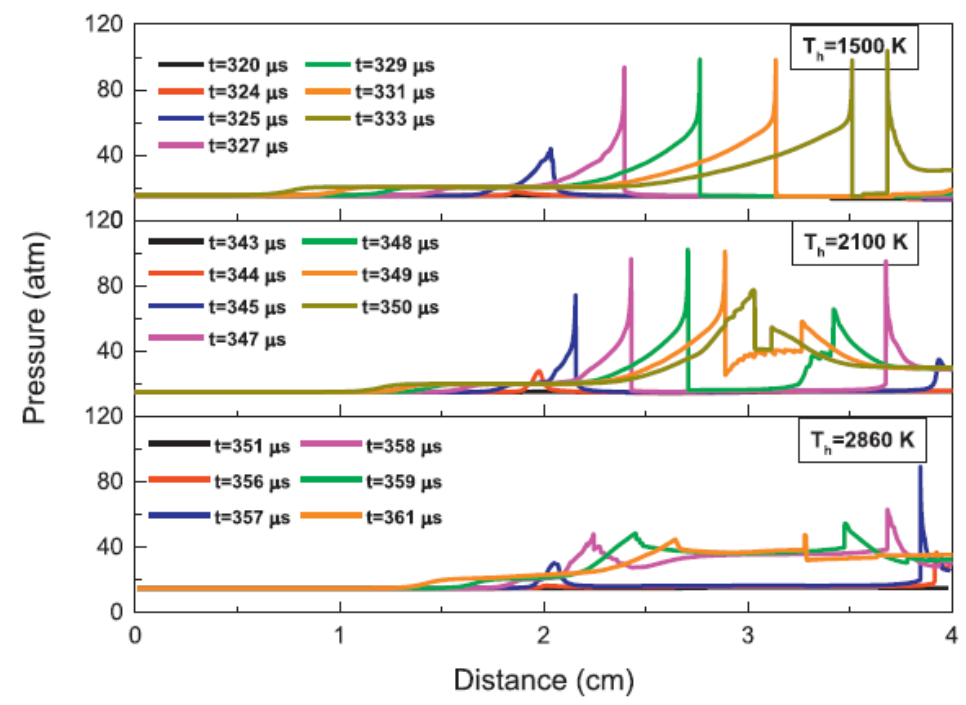

(b)

Figure 15 Temporal sequences of (a) temperature and (b) pressure at $P_{0}=10 \mathrm{~atm}$ and $T_{0}=1050 \mathrm{~K}$ for different ignition temperatures.

Despite these observations in common, some important distinctions are also observed as initial pressure is raised. Firstly, the pressure peak of Al reaction font is significantly increased up to a level of $P_{\max }=100 \mathrm{~atm}$, which is three times higher than that of $P_{0}=5 \mathrm{~atm}$ case. This can be attributed to the improvement of energy density for the mixture in constant-volume reactor, as suggested in [1]. Secondly, auto-ignition mode transition from detonation to supersonic deflagration is observed under the same ignition temperature conditions, e.g. the pressure peak of end-wall auto-ignition front at $T_{h}=2100 \mathrm{~K}$ initially increases up to $P_{\max }=100 \mathrm{~atm}$ and then decreases to $P_{\max }=$ $60 \mathrm{~atm}$, accompanied by gradually enhanced pre-flame partial reaction.

These observations can be further validated through the analysis of Al reaction front speed at different ignition temperatures, as shown in Figure 16. It is observed that for $T_{h}=1500 \mathrm{~K}$ case, both end-wall and pre-flame auto-ignition development end in a detonation wave propagation with a velocity closing to C-J detonation speed. For the case of $T_{h}=2100 \mathrm{~K}$, similar observation is obtained for the pre-flame auto-ignition, but there is a transition from the sub-sonic to supersonic 
level for the reaction front from end-wall auto-ignition. Further increases in ignition temperature to $T_{h}=2860 \mathrm{~K}$, the reaction fronts of both end-wall and pre-flame auto-ignition propagate with a velocity far beyond C-J detonation speed. These results again elucidate that the auto-ignition mode transition from detonation to supersonic deflagration is still maintained at elevated initial pressure with pressure wave disturbance.

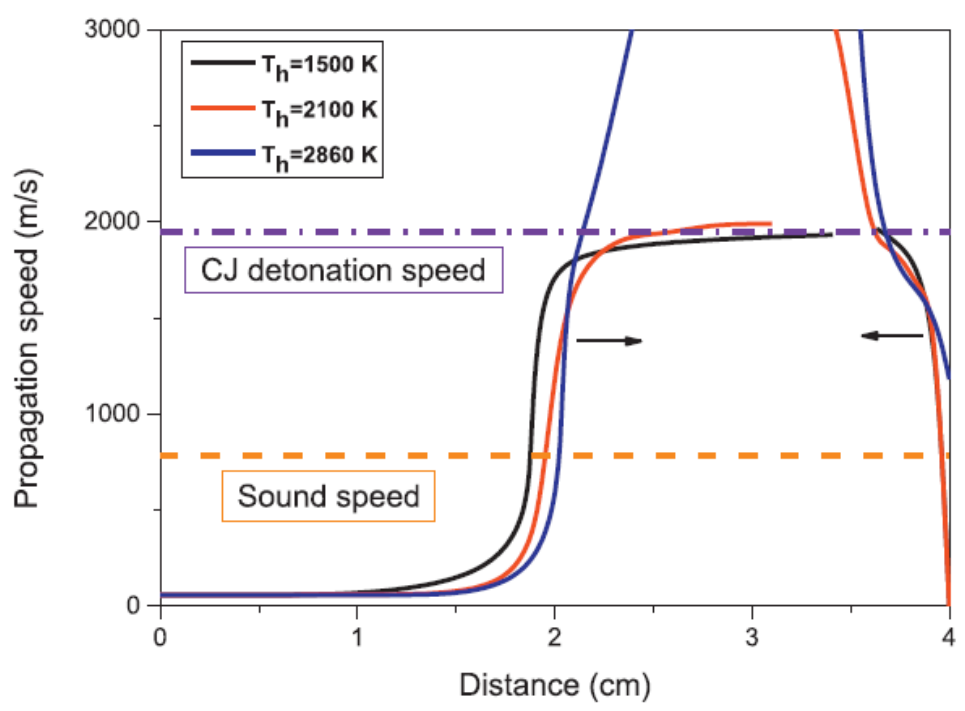

Figure 16 Auto-ignition reaction front speed of different ignition temperatures for $P_{0}=10 \mathrm{~atm}$ and $T_{0}=1050 \mathrm{~K}$ case, with sound speed and C-J detonation speed for comparisons.

\subsection{Quantification in Bradley's diagram}

To quantify the auto-ignition mode transition and knocking intensity modified by pressure wave disturbance, Bradley's diagram [10-12,33] is introduced here to evaluate all computation cases in current work. In Bradley's diagram, there are two non-dimensional parameters $(\xi, \varepsilon)$, where $\xi$ describes the coupling between acoustic wave and reaction front, and $\varepsilon$ evaluates the rapidity of chemical energy release within a hot-spot,

$\xi=a / u_{a i}=a /\left(\delta \tau_{a i} / \delta x\right)^{-1}$

$\varepsilon=\tau_{p} / \tau_{e}=\left(r_{0} / a\right) / \tau_{e}$

where $a$ is local sound speed, $u_{a i}$ is the speed of auto-ignition reaction front, $\tau_{a i}$ is auto-ignition delay time, $x$ is the spatial coordinate of reactive zone, $r_{0}$ is the radius of hot-spot, and $\tau_{e}$ is the excitation time defined as the time interval between $5 \%$ and maximum heat release rate. It should be noted that $\delta \tau_{a i} / \delta x$, the igntion delay time gradient, allows for the transient temperature, pressure and species concentration at auto-ignition moment in this work.

Here hot-spot radius is obtained through $\mathrm{OH}$ mass fraction distribution and knocking intensity is defined as the pressure peak of Al reaction front. To obtain ignition delay time of local mixture, both transient thermodynamic state and species concentration of all grid nodes in computation domain are extracted and then utilized in CHEMKIN SENKIN package [32] for calculation. Corresponding results are summarized in Figure 17. It shows that as initial temperature is raised from $T_{0}=900$ to 
$1050 \mathrm{~K}$, there is a sharp decrease in knocking intensity, and this trend becomes less obvious when initial temperature is beyond $T_{0}=1050 \mathrm{~K}$. Such that it renders a logarithmic function between knocking intensity and initial temperature. Feasible explanation is that the energy density of fuel/air mixture in constant-volume reactor is reduced as initial temperature is raised for given ambient pressure. Therefore, knocking intensity would be much stronger at lower temperature as long as residence time is long enough to allow local auto-ignition occurrence. With the weakness of pressure wave disturbance at higher ignition temperature, knocking intensity is reduced from sufficiently high level similar to super-knock to that of conventional knock.
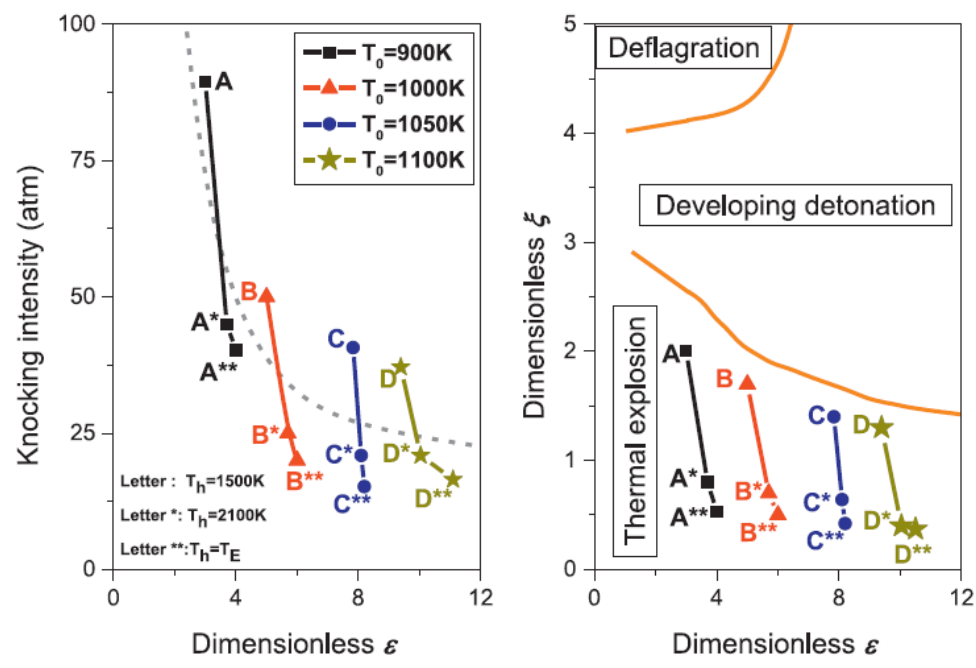

Figure 17 Summary of auto-ignition mode and knocking intensity at different conditions in non-dimensional Bradley's diagram.

Furthermore, it is noted that knocking intensity is closely associated with auto-ignition mode. Figure 17 shows that with the variations of pressure wave disturbance at different initial temperatures and ignition temperatures, there is an obvious alteration for the location of auto-ignition mode in Bradley's diagram, even though all cases are located in thermal explosion regime. The main reason for this is that Bradley's diagram is constructed on basis of initially non-reactive flows; however, it has become much reactive for the surrounding mixture at auto-ignition moment in current work. But in spite of this auto-ignition mode transition is qualitatively consistent with the distribution of combustion regimes in the $(\xi, \varepsilon)$ diagram, where $T_{h}=1500 \mathrm{~K}$ case is close to the lower boundary of developing detonation regime and the one with largest ignition temperature (e.g. $T_{h}=2743 \mathrm{~K}$ for $T_{0}=900 \mathrm{~K}$ case) tends to approach supersonic deflagration regime (ideally thermal explosion regime).

\section{Conclusions}

In this work, one-dimensional direct numerical simulations with detailed kinetics and transport properties were performed to study the role of pressure wave disturbance in auto-ignition mode transition and knocking intensity under enclosed conditions. With well-defined initial and boundary conditions, the most essential physics and chemistry during local auto-ignition and knocking combustion have been obtained. 
First, pressure wave disturbance is an essential feature for the combustion under enclosed conditions. Through adjusting ignition temperature of hot ignition kernel, a pressure wave disturbance with different levels in strength can be obtained. It shows that as the increases of ignition temperature at each initial temperature, pressure wave strength is decreased monotonically as a consequence of the reduction in energy density of hot ignition kernel. Meanwhile, it is found that pressure wave strength mainly depends on the thermodynamic state of hot ignition kernel, and corresponding temperature rise is determined by the thermodynamic state both inside and outside of hot ignition kernel.

Second, pressure wave disturbance does not affect the auto-ignition location in reactive flows, but it has significant impact on auto-ignition timing and mode development. As the weakness of pressure wave strength at each initial temperature, three auto-ignition modes (i.e. detonation, mixed mode and supersonic deflagration) have been sequentially observed. This is further validated by the propagation speed of auto-ignition reaction front. The essential role of pressure wave disturbance in auto-ignition mode transition can be attributed to the partial reaction of local mixture ahead of auto-ignition reaction front. Furthermore, similar variations in auto-ignition mode caused by pressure wave disturbance are still maintained at elevated pressure conditions.

Third, Bradley's diagram is introduced to quantify auto-ignition mode transition and knocking intensity. It shows that both initial thermodynamic state and auto-ignition mode can affect knocking intensity, but the modifications in knocking intensity by pressure wave disturbance are mainly ascribed to auto-ignition mode transition. With auto-ignition mode transition from detonation to supersonic deflagration, knocking intensity varies from sufficiently high level similar to super-knock to that of conventional knock. Meanwhile, it is found that some deviations do exist due to initially non-reactive assumptions for Bradley's diagram; however, it is qualitatively consistent with the distribution of combustion regimes in the diagram for auto-ignition mode and its transition.

Current work shall give insights into the role of flow disturbance (e.g. pressure wave and turbulent fluctuations) on auto-ignition mode and knocking intensity under engine-like conditions. Meanwhile, it is able to provide fundamental theory guidance for the suppression and regulation of knocking combustion like conventional knock and super-knock in engines.

\section{Acknowledgment}

This work was supported by Major Research Plan of National Natural Science Foundation of China (91641203), National Natural Science Foundation of China (Grant No. 51476114), China Postdoctoral Science Foundation (2016M590201), Tianjin Natural Science Foundation (17JCZDJC31500), Tianjin Science \& Technology Supporting Program (13ZCZDGX04400).

\section{References}

[1] Z. Wang, H Liu , R.D. Reitz, Knocking combustion in spark-ignition engines, Prog. Energ. Combust. 61 (2017) 78-112. 
[2] J.Y. Pan, G.Q. Shu, H.Q. Wei, Interaction of flame propagation and pressure waves during knocking combustion in spark-ignition engines, Combust. Sci. Technol. 186 (2014) 192-209.

[3] S. Pischinger, M. Günther, O. Budak, Abnormal combustion phenomena with different fuels in a spark ignition engine with direct fuel injection, Combust. Flame 175 (2017) 123-137.

[4] N. Peters, B. Kerschgens, G. Paczko, Super-knock prediction using a refined theory of turbulence, SAE Int. J. Engines 6 (2013) 953-967.

[5] K. Tanoue, T. Jimoto, T. Kimura, M. Yamamoto, J. Hashimoto, Effect of initial temperature and fuel properties on knock characteristics in a rapid compression and expansion machine, Proc. Combust. Inst. 36 (2017) 3523-3531.

[6] J. Rudloff, J.M. Zaccardi, S. Richard, Analysis of pre-ignition in highly charged SI engines: emphasis on the auto-ignition mode, Proc. Combust. Inst. 34 (2013) 2959-2967.

[7] W.Q. Sun, S.H. Won, X.L. Gou, Y. Ju, Multi-scale modeling of dynamics and ignition to flame transitions of high pressure stratified n-heptane/toluene mixtures, Proc. Combust. Inst. 35 (2015) 1049-1056.

[8] A.B. Mansfield, M.S. Wooldridge, High-pressure low-temperature ignition behavior of syngas mixtures, Combust. Flame 161 (2014) 2242-2251.

[9] Y.B. Zeldovich, Regime classification of an exothermic reaction with nonuniform initial conditions, Combust. Flame 39 (1980) 211-214.

[10] D. Gu, D. Emerson, Bradley, Modes of reaction front propagation from hot spots, Combust. Flame 133 (2003) 63-74.

[11] D. Bradley, G.T. Kalghatgi, Influence of auto-ignition delay time characteristics of different fuels on pressure waves and knock in reciprocating engines, Combust. Flame 156 (2009) 2307-2318.

[12] L. Bates, D. Bradley, G. Paczko, N. Peters, Engine hot spots: Modes of auto-ignition and reaction propagation, Combust. Flame 166 (2016) 80-85.

[13] A. Robert, S. Richard, O. Colin, T. Poinsot, LES study of deflagration to detonation mechanisms in a downsized spark ignition engine, Combust. Flame 162 (2015) 2788-2807.

[14] P. Dai, Z. Chen, S. Chen, Y. Ju, Numerical experiments on reaction front propagation in $n-$ heptane/air mixture with temperature gradient, Proc. Combust. Inst. 35 (2015) 3045-3052.

[15] T.H. Zhang, W.Q. Sun, Y.G. Ju, Multi-scale modeling of detonation formation with concentration and temperature gradients in n-heptane/air mixtures, Proc. Combust. Inst. 36 (2017) 1539-1547.

[16] P. Pal, M. Valorani, P.G. Arias, Computational characterization of ignition regimes in a syngas/air mixture with temperature fluctuations, Proc. Combust. Inst. 36 (2017) 3705-3716.

[17] J.Y. Pan, H.Q. Wei, G.Q. Shu, Z. Chen, P. Zhao, The role of low temperature chemistry in combustion mode development under elevated pressures, Com- bust. Flame 174 (2016) 179-193. 
[18] M.F. Ivanov, A.D. Kiverin, M.A. Liberman, Ignition of deflagration and detonation ahead of the flame due to radiative preheating of suspended micro particles, Combust. Flame 162 (2015) 36123621.

[19] M.A. Liberman, M.F. Ivanov, O.E. Peil, Numerical modeling of the propagating flame and knock occurrence in spark-ignition engines, Combust. Sci. Technol. 177 (2004) 151-182.

[20] M.A. Liberman, M.F. Ivanov, D.M. Valiev, Hot spot formation by the propagating flame and the influence of EGR on knock occurrence in SI engines, Combust. Sci. Technol. 178 (2006) 1613-1647.

[21] N. Kawahara, E. Tomita, Visualization of auto-ignition and pressure wave during knocking in a hydrogen park-ignition engine, Int. J. Hydrogen Energ. 34 (2009) 3156-3163.

[22] Y.L. Qi, Z. Wang, J.X. Wang, X. He, Effects of thermodynamic conditions on the end-gas combustion mode associated with engine knock, Combust. Flame 162 (2015) 4119-4128.

[23] J.Y. Pan, G.Q. Shu, P. Zhao, H.Q. Wei, Z. Chen, Interactions of flame propagation, auto-ignition and pressure wave during knocking combustion, Combust. Flame 164 (2016) 319-328.

[24] H. Yu, Z. Chen, End-gas autoignition and detonation development in a closed chamber, Combust. Flame 162 (2015) 4102-4111.

[25] Z. Chen, M.P. Burke, Y. Ju, Effects of Lewis number and ignition energy on the determination of laminar flame speed using propagating spherical flames, Proc. Combust. Inst. 32 (2009) 1253-1260.

[26] R. Kee, J. Grcar, M. Smooke, J. Miller, A fortran program for modeling a steady laminar onedimensional premixed flame, Sandia Report No. SAND85-8240, Sandia National Laboratories, Livermore, CA, USA, 1987.

[27] Z. Chen, On the extraction of laminar flame speed and Markstein length from outwardly propagating spherical flames, Combust. Flame 158 (2011) 291-300.

[28] W.K. Zhang, Z. Chen, W.J. Kong, Effects of diluents on the ignition of premixed H2/air mixtures, Combust. Flame 159 (2012) 151-160.

[29] Z. Chen, Studies on the initiation, propagation, and extinction of premixed flames Ph.D. Thesis, Princeton University, Princeton, NJ, USA, 2008.

[30] C.K. Law, Combustion physics, Cambridge University Press, 2006.

[31] M.P. Burkel, M. Chaos, Y. Ju, F.L. Dryerl, S.J. Klippenstein, Comprehensive H2/O2 kinetic model for high-pressure combustion, Int. J. Chem. Kinet. 44 (2012) 44 4-474.

[32] A.E. Lutz, R.J. Kee, J.A. Miller, H.A. Dwyer, A.K. Oppenheim, Twenty-Second Symposium (International) on Combustion Dynamic Effects Of Auto-Ignition Centers For Hydrogen and C1,2Hydrocarbon Fuels, Pittsburgh (1989).

[33] D. Bradley, Hot spots and gasoline engine knock, J. Chem. Soc., Faraday Trans 92 (1996) 29592964. 